\title{
Spontaneous Pregnancy following Treatment of Symptomatic Uterine Myomatosis with Ulipristal Acetate without Surgery
}

\begin{abstract}
Vicente Spinoso Cruz ${ }^{{ }^{*}}$, Marta Colechá Morales ${ }^{1}$, Ligia Gil Melgosa ${ }^{1}$ and Aida Revuelta Lopez ${ }^{1}$
${ }^{1}$ Servicio de Obstetricia y Ginecología, Hospital Obispo Polanco de Teruel, Av. Ruiz Jarabo, s/n, 44002 Teruel, Spain.

* Corresponding Author: Vicente Spinoso, Servicio de Obstetricia y Ginecología, Hospital Obispo Polanco de Teruel, Av. Ruiz Jarabo, s/n, 44002 Teruel, Spain.

Received date: January 25, 2021; Accepted date: February 15, 2021; Published date: April 09,2021

Citation: Vicente S. Cruz, Marta C. Morales, Ligia G. Melgosa, Aida R. Lopez (2021) Spontaneous pregnancy following treatment of symptomatic uterine myomatosis with Ulipristal Acetate without surgery J. Obstetrics Gynecology and Reproductive Sciences 5(3); DOI: $10.31579 / 2578-8965 / 059$

Copyright: @ 2021 Vicente Spinoso Cruz, This is an open access article distributed under the Creative Commons Attribution License, which permits unrestricted use, distribution, and reproduction in any medium, provided the original work is properly cited.

Abstract

Uterine fibroids are the most frequent gynaecological benign tumors in women of reproductive age and can cause infertility. Their treatment may be medical, surgical or a combination of both, but they may compromise future fertility in patients in which their wish to conceive has not yet been fulfilled. In this report we present two patients with symptomatic uterine myomas and who wanted to preserve their fertility. Treatment with one or two 12-week courses of $5 \mathrm{mg}$ of ulipristal acetate was prescribed. A decrease in the size of the fibroids was observed, along with adequate control of the symptoms. Spontaneous pregnancies led to two live births without significant complications. Treatment with Ulipristal Acetate may be an effective option to take into account in the management of patients with symptomatic uterine fibroids who refuse surgery or in those in which it is contraindicated and who wish to preserve their fertility.
\end{abstract}

Keywords: cases report; pregnancy; uterine fibroids; ulipristal acetate

\section{Abbreviations}

CRL: Crown-rump length

FHR: Fetal Heart Rate

Hb: Haemoglobin

Hct: Haematocrit

SPRM: Selective Progesterone Receptor Modulator

UPA: Ulipristal Acetate

\section{Introduction}

Uterine leiomyomas are the most common benign tumors in women of reproductive age [1-3]. Although many of them are asymptomatic and frequently undiagnosed, a significant percentage cause important symptoms such as heavy menstrual bleeding, pelvic pain and pressure, anaemia and decreased quality of life [3]. Depending on the anatomical location, they can also cause infertility and an increased risk of abortion [4]. Specifically, those fibroids distorting the uterine cavity can cause alterations in sperm migration, interfere with embryo transport due to affected uterine contractility, and also involve eventual implantation failures as a consequence of impaired endometrial vascularization [5].

The therapeutic approach to treat symptomatic uterine fibroids can be medical, surgical or a combination of both options. However, the optimal treatment would be the one that produces relief or disappearance of symptoms, reduction of fibroids' volume or their eventual total shrinkage and improvement of fertility rates [6].

Ulipristal Acetate (UPA) is a selective progesterone receptor modulator (SPRM) that has been approved as medical treatment of uterine fibroids in Europe [7]. Its effectiveness in doses of 5 to $10 \mathrm{mg}$ daily during 13week cycles has been demonstrated, controlling excessive bleeding and reducing fibroids' size [8]. It's been also shown as effective as Leuprolide Acetate for the control of bleeding and the decrease in fibroid volume, but with a statistically significant reduction in the reporting of hot flashes when compared to the latter [9]. Endometrial changes related to UPA treatment - have been described, which are benign and reversible a few weeks after stopping treatment. No development of endometrial hyperplasia or adenocarcinoma have been reported [10-11].

There is little evidence reporting the utility of UPA for the treatment of uterine fibroids with a view to improving fertility rates [12]. However, cases reported in Poland [12] and Spain [13] and also the follow-up of 21 patients who came from a pivotal phase III study with UPA in Europe offer good expectations [14]. Khulood et al [6] described in 2016 the first term pregnancy in a patient with symptomatic uterine myomatosis previously treated with UPA without surgery. In our series, we describe two cases with the same characteristics that demonstrate the utility of this drug in improving spontaneous fertility rates without additional treatments.

\section{Case 1 report}


42-year-old patient, G0, came to the medical consultation presenting a 6month course of pressure at the hypogastric level and menstrual disorders (hypermenorrhea) for 3 months. As a relevant antecedent, the patient referred myomectomy 12 years ago through laparotomy. On physical examination, it was confirmed the presence of a firm mass at the hypogastric level, approximately $5 \mathrm{~cm}$ above the pubic symphysis, not painful on palpation and introduced into the pelvic cavity. A transvaginal ultrasound was performed, showing a heterogeneous uterus of $112.6 \mathrm{x}$ 100.4 x $63.2 \mathrm{~mm}$, where at least 4 fibroids were counted (Figure 1):
A) Anterior myoma measuring 24 × $30 \mathrm{~mm}$, type V FIGO classification

B) Posterior myoma measuring $29 \times 24 \mathrm{~mm}$, type V FIGO classification

C) Fundic myoma measuring 35 x 25 mm, type VI FIGO classification

D) Left transmural myoma measuring 51 x $40 \mathrm{~mm}$, type III-V, FIGO classification.

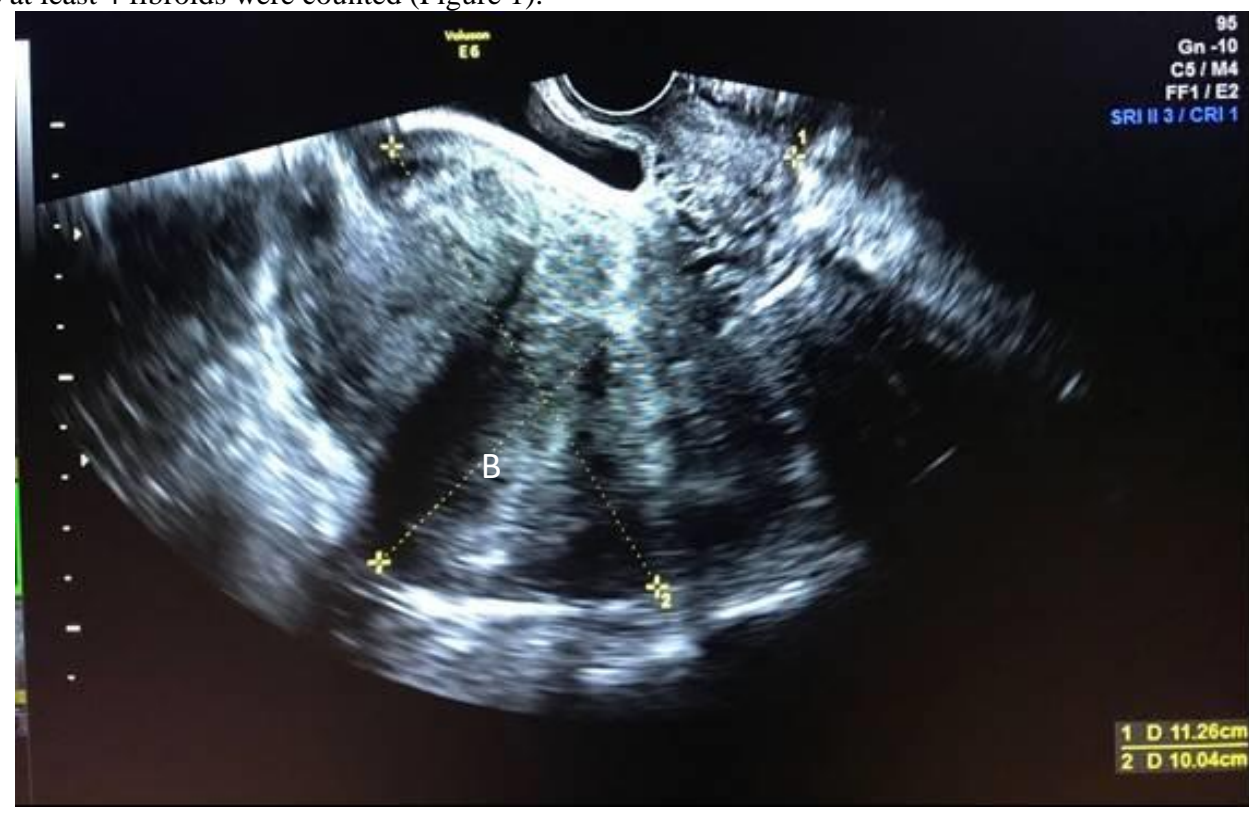

Figure 1. Anterior (A) and posterior (B) fibroid (before pregnancy)

Lab tests showed Haemoglobin $(\mathrm{Hb})$ levels of $10.4 \mathrm{~g} / \mathrm{dL}$ and Haematocrit (Hct) of $31.1 \%$, with a normal biochemistry. The patient had still a wish to conceive, so it was decided to start treatment with UPA $5 \mathrm{mg} /$ day in two courses of 12 weeks each and re-evaluation.

During the treatment, the patient reported pain relief in the hypogastrium and improvement in hypermenorrhea. The haematological profile showed values of $\mathrm{Hb}: 13.4 \mathrm{~g} / \mathrm{dL}$ and Hct: $40.1 \%$; transaminases were within normal limits. As a side effect, few and irregular spotting was reported during treatment.
After completing the two courses of UPA, the patient came to the medical consultation for control visit, reporting an 8-week course secondary amenorrhea . A pregnancy test was performed, being positive. A transvaginal ultrasound showing a gestational sac in situ with an embryo inside with a crown-rump length (CRL) of $4.2 \mathrm{~mm}$ corresponding to $6 \mathrm{~W}$ $+1 \mathrm{D}$ and positive Fetal Heart Rate (FHR) quantified at $107 \mathrm{x}^{\prime}$ (Figure 2). It was concluded that the patient presented spontaneous ovulation approximately 2 weeks after finishing the treatment. 


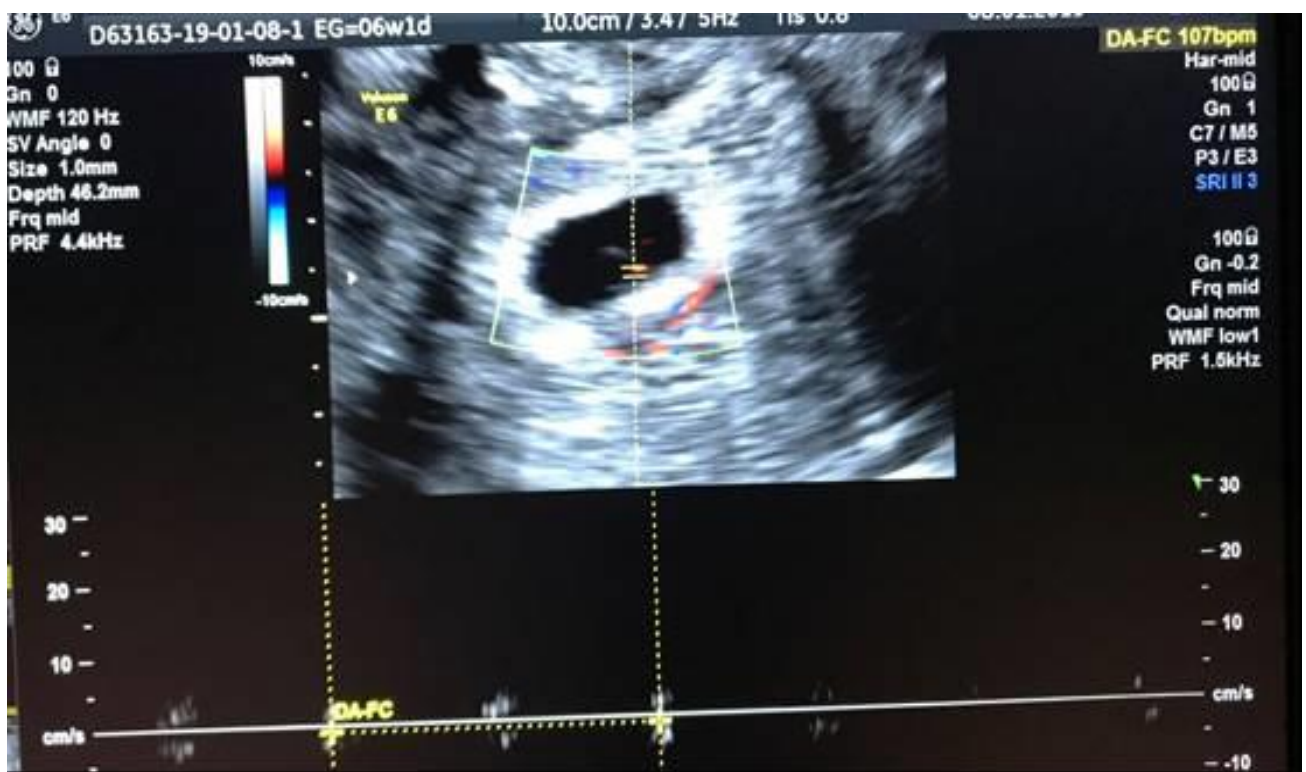

Figure 2. Positive Fetal Heart Rate

During pregnancy follow-up an increase of the volume of the fibroids until 12 weeks was confirmed, without presenting relevant complications. At 20 weeks the size of fibroids were:

A) Anterior myoma, lower third, close to the cervix measuring $31 \times 44$ $\mathrm{mm}$,

B) Posterior myoma, lower third, close to the cervix measuring $45 \times 38$ $\mathrm{mm}$

C) Fundic myoma measuring $49 \times 35 \mathrm{~mm}$

D) Left myoma measuring $70 \times 60 \mathrm{~mm}$, type IV-V FIGO classification

The patient developed gestational diabetes which was controlled with diet. At 39 weeks, caesarean was performed, obtaining a healthy female newborn with a birth weight of $2,930 \mathrm{Kg}$, Apgar score of 9 and 10 points and a cord $\mathrm{pH}$ of 7.31. Mother and daughter are discharged on the third day of surgery without complications. Mother Breastfed for 9 months and at 3 months post-cesarean section, a transvaginal ultrasound was performed, showing a notable reduction in the size of the fibroids (no myoma observed in anterior uterus surface):
A) Posterior myoma measuring 24 x $20 \mathrm{~mm}$, type V FIGO classification
B) Fundic fibroid measuring $28 \times 21 \mathrm{~mm}$, type VI FIGO classification
C) Left transmural myoma measuring $35 \times 25 \mathrm{~mm}$, type IV FIGO classification (Figure 3).

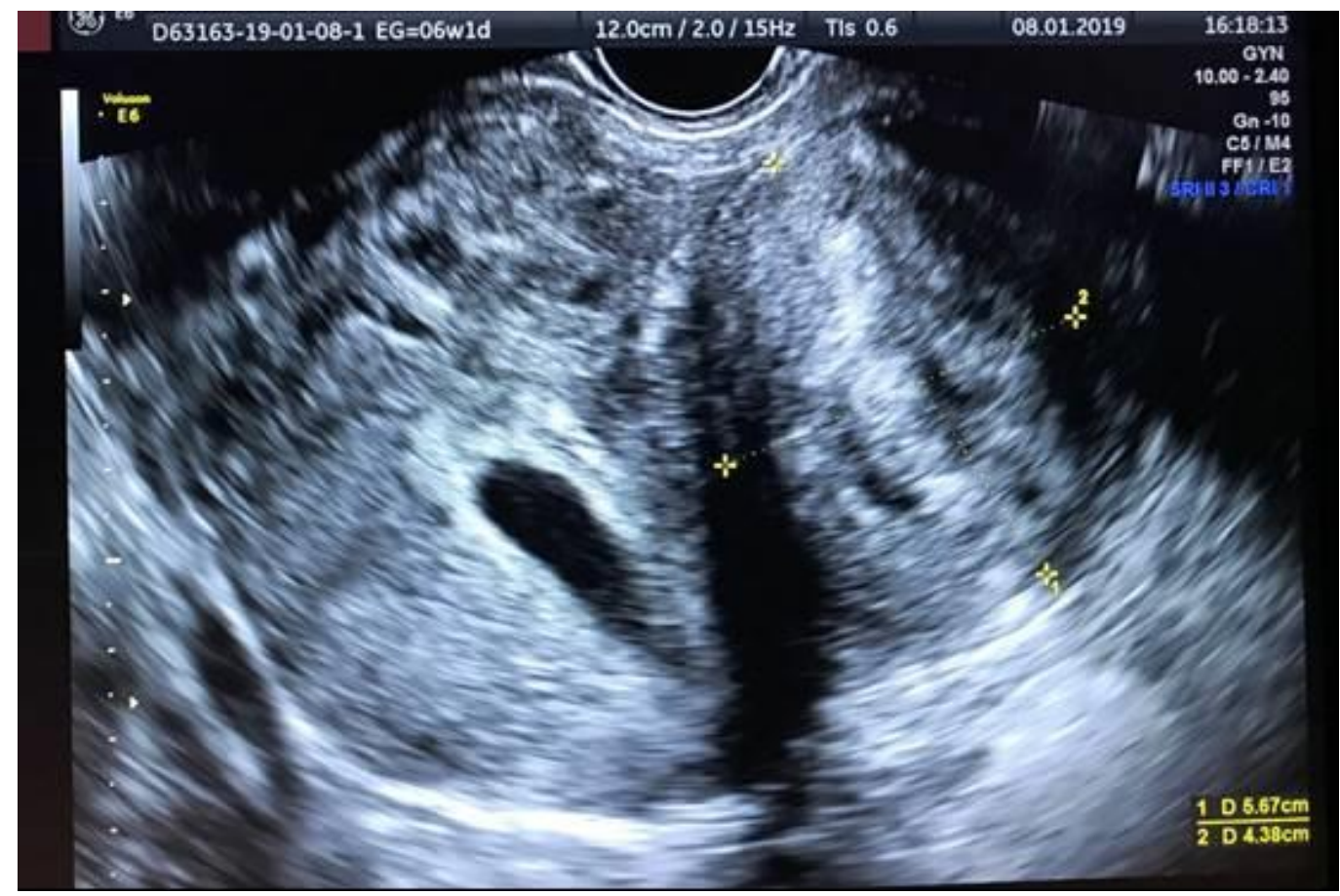


Figure 3. Left transmural myoma in pregnancy diagnosis moment

\section{Case 2 report}

A 35-year-old patient, G2 / P1 / A1, consulted for presenting menstruation with a tendency to be hypermenorrheal for 7 months, treated with combined oral contraceptives without significant improvement. Then, transvaginal ultrasound was performed, showing:

A) Subserous myoma in fundus measuring $19 \times 21 \mathrm{~mm}$, type VI FIGO classification

B) Posterior submucous myoma measuring 23 x $23 \mathrm{~mm}$, type II FIGO classification

C) Posterior submucous myoma measuring 17 x $15 \mathrm{~mm}$, type II FIGO classification
D) Anterior submucous myoma measuring $15 \times 14 \mathrm{~mm}$, type II FIGO classification

Laboratory analysis revealed values of $\mathrm{Hb}$ of $10.9 \mathrm{~g} / \mathrm{dL}$ and Hct: $32.1 \%$, with a normal biochemistry. Based on the symptomatology and the lab tests results it was decided to prescribe treatment with UPA $5 \mathrm{mg} /$ day for 12 weeks (one course). The patient was also appointed to incorporate to the hospital's surgical waiting list, proposing resection of submucous fibroids by hysteroscopy.

8 weeks after completing UPA treatment, the patient went to the gynecology clinic, reporting secondary amenorrhea just after UPA cessation, concomitantly nausea, vomiting and occasional dizziness for approximately 2 weeks. Transvaginal ultrasound was repeated, showing (Figure 4):

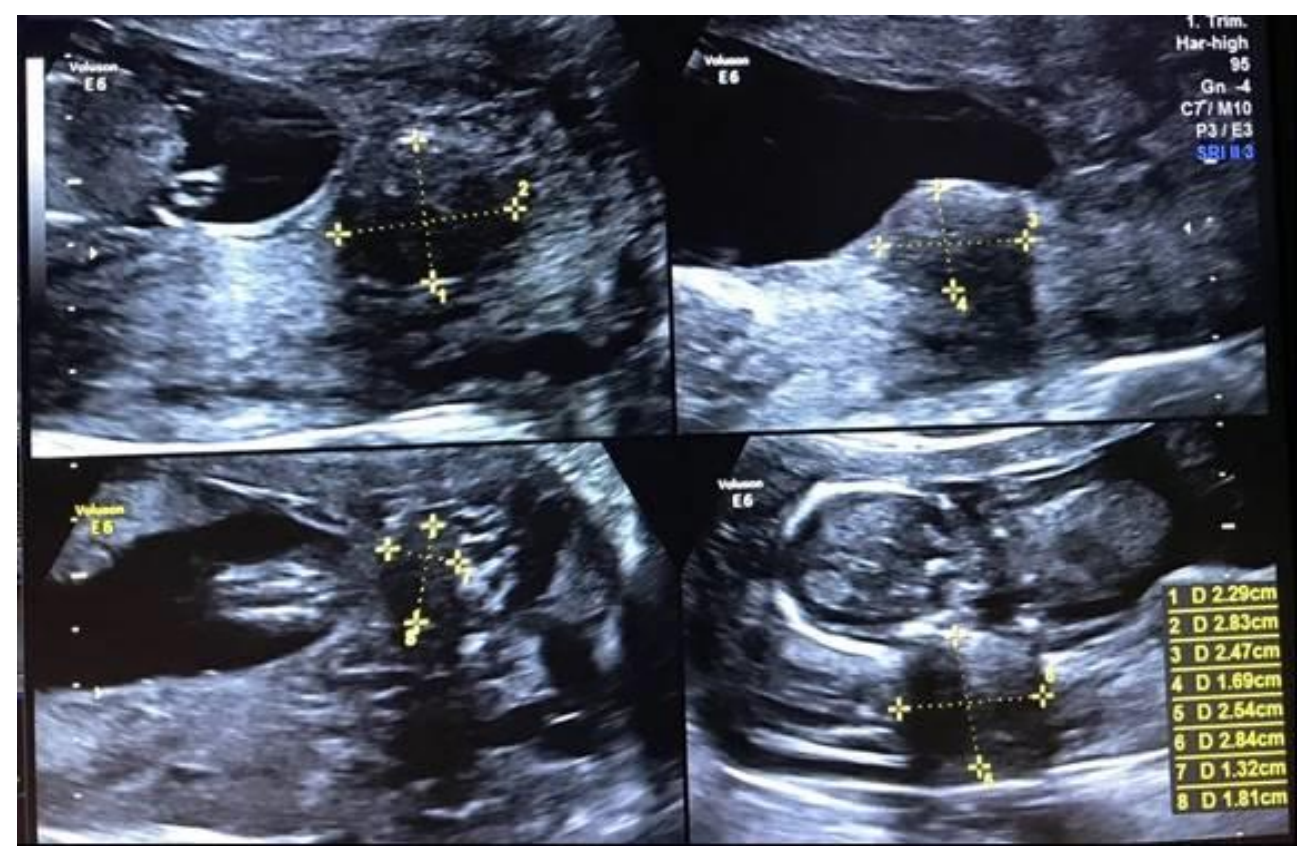

Figure 4. Intramural myoma (A); posterior myoma (B); posterior myoma (C); posterior myoma (D)

A) Intramural myoma measuring $15 \times 17 \mathrm{~mm}$, type II FIGO classification

B) Posterior myoma measuring $19 \times 18 \mathrm{~mm}$, type II FIGO classification

C) Posterior myoma measuring 15 x 13 mm, type II FIGO classification

D) Posterior myoma measuring 11 x $10 \mathrm{~mm}$, type II FIGO classification

E) Presence of a gestational sac in uterus with an embryo inside with a CRL of $3.25 \mathrm{~mm}$. corresponding to 5.5 weeks and a positive FHR quantified at $116 x^{\prime}$.

During pregnancy follow-up an increase in the volume of the fibroids until 12 weeks of gestation was confirmed, without significant complications.

A) Intramural myoma measuring 22.9 × $28.3 \mathrm{~mm}$, type II FIGO classification

B) Posterior myoma measuring 24.7 x $16.9 \mathrm{~mm}$, type II FIGO classification

C) Posterior myoma measuring 28.4 x $25.4 \mathrm{~mm}$, type II FIGO classification
D) Posterior myoma measuring 18 x $13 \mathrm{~mm}$, type II FIGO classification

The patient underwent gestational diabetes during pregnancy, requiring insulin and diet treatment. At 39 weeks gestation was completed by labor induction, obtaining a male newborn with a birth weight of $3,710 \mathrm{Kg}$, an Apgar score of 9 and 10 points and a cord $\mathrm{pH}$ of 7.22, eutocic delivery without complications. Mother and son were then discharged on the second day of the puerperium without incidents. The mother breastfed for 6 months and at 3 months postpartum a transvaginal ultrasound was performed, showing a notable reduction in the size of the fibroids:

A) Intramural fibroid measuring $13 \times 13 \mathrm{~mm}$, type III FIGO classification

B) Posterior myoma measuring 12 x $11 \mathrm{~mm}$, type III FIGO classification

C) Posterior myoma measuring 9 x $10 \mathrm{~mm}$ type III FIGO classification

D) Visualization of the smallest posterior myoma was not achieved

All fibroids had a low submucosal component (type III FIGO classification), so it was decided to insert an intrauterine device that releases levonorgestrel. She remains asymptomatic to date. 


\section{Discussion}

Uterine fibroids have a high impact on the quality of life of patients due to their high morbidity and, despite of their benignity, they can produce heavy menstrual bleeding, pelvic pain, pressure symptoms, infertility, and obstetric complications [3].

Multiple treatments (medical, surgical or a combination of both), have been described for uterine fibroids with a high variable response [16, 17]. However, when choosing a treatment it is essential to take into consideration the patient's age and her desire to preserve fertility. Women with uterine leiomyomas who still wish to conceive may face a dilemma since there are not many therapeutic options available to warrant that goal.

UPA, a member of the selective progesterone receptor modulator (SPRM) family, was approved for the treatment of uterine leiomyomas in Canada, Europe, and numerous countries worldwide [14]. Many studies have demonstrated the efficacy of UPA in controlling menorrhagia and reducing the volume of uterine fibroids in symptomatic patients $[8,9$, and 10].

In the two clinical cases described, AUP $5 \mathrm{mg} /$ day for 12 weeks in one or two cycles successfully reduced the volume of the fibroids and allowed the recovery of the normal anatomy of the uterine cavity. This improvement was at least enough to enable an embryo implantation. Although the possible changes in endometrial histology after the end of treatment were not examined, the final outcome was that both patients became pregnant and they had pregnancies with few complications.

This work is added to other existing publications [12, 13, 18-22] that showed the use of UPA in the management of patients with uterine myomatosis who still wish to conceive, and who reject a surgical option since, this option compromised their fertility. In addition to successfully reduce fibroid volume and improve symptoms, the use of UPA avoid the inherent risks of surgery on reproductive capacity, and appear to have no deleterious effects on pregnancy. That is why we think that UPA may be considered a therapeutic alternative in an immediate attempt to achieve conception at the end of treatment [13]. However, in order to be able to make a recommendation based on scientific evidence, the authors advocate conducting prospective studies in the future to establish the safety of this drug as a treatment option for symptomatic uterine fibroids before pregnancy.

\section{Conclusion}

Treatment with Ulipristal Acetate may be an effective option in women with symptomatic uterine fibroids unable to conceive and who refuse surgery or surgery is contraindicated. Clinical studies should be carried out to confirm this finding.

\section{Data Availability}

The data used to support the findings of this study are available from the corresponding author upon request.

\section{Conflicts of Interest}

The authors declare that there is no conflict of interest regarding the publication of this paper.

\section{Funding Statement}

This study was sponsored by Gedeon Richter Ibérica SA.

\section{Reference}

1. Evans F, Brunsdl S. (2007) Uterine fibroid tumors: diagnosis and treatment. Am Fam Physician; 75:1503-8.
2. Cramer S, Panel A. (1990) The frecuency of uterine leiomyomas. Am J Clin Pathol; 94: 435-8.

3. Fields K R, Neinstein L S. (1996) Uterine myomas in adolescents: case reports and a review of the literature. $J$ Pediatr Adolsc Gynecol; 9(4):195-8.

4. Donnez E, Sikirica V, Grabert-Estelles J, Bolle SC, Dodd SL, Maroulis C, et al. (2010) The burden of uterine fibroids in five european countries. Eur J Obstet Gynecol Reprod Biol; 152: 96102.

5. Donnez J, Jadoul P. (2002) What are the implications of myuomas on fertility? A need for debate? Hum Reprod; 17: 1424-31.

6. Khulood M, MD, MRCOG, FRCSC. (2016) Spontaneous pregnancy following ulipristal acetate treatment in a woman with symtomatic uterine fibroid. J Osbtet Gynaecol Can; 38 (1): 75-79.

7. Electronic Medicines Compendium, "Esmya 5 mgr tablets (ulipristal acetate)".

8. Donnez J, Tatarchuck TF, Buchard P, et al. (2012) Ulipristal Acetate versus placebo for fibroid treatment before surgery. $N$ Engl J Med; 366 (5): 409-420.

9. Donnez J, Vazquez F, Tomaszewski J, et al. (2012) Ulipristal Acetate vs Leuprolide Acetate for uterine fibroids. $N$ Engl J Med; 366 (5): 421-432.

10. Donnez J, Tomaszewski J, Vazquez F, et al. (2014) Long term treatment of uterine fibroids with ulipristal acetate. Fertil Steril; 101 (6): 1565-1573.

11. Williams ARW, Bergelon C, Barlow DH, Forenczy A. (2012) Endometrial morphology ater treatment of uterine fibroids with the selective progesterone receptor modulator, ulipristal acetate. Int J Gynecol Pathol; 31 (6):556-569.

12. Wdowiak A. (2013) Pretreatment with ulipristal acetate before ICSI procedure: a case report. Przglad Menopauzalnyy; 6: 496500.

13. Monleón J, Martinez-Varea A, Galliano D, Pellicer A. (2014) Succesful pregnancy after treatment with ulipristal acetate for uterine fibroids. Case Report Obstet Gynecol; 314587.

14. Ali M, Al-Hendy A. (2017) Selective progesterone receptor modulators for fertility preservation in woman with symptomatic uterine fibroids. Biol of Reprod; 97 (3):337-352.

15. Talaulikar VS, Mandoya IT. (2012) Ulipristal Acetate: a novel Error! Hyperlink reference not valid.option for the medical managment of symptomatic uterine fibroids. Adv Ther; 29: 65563.

16. Miller CE. (2009) Unmet Therapeutic needs for uterine myomas. J minim Invasive Gynecol; 16: 11-21.

17. Lumsden MA. (2010) Modern managment of fibroids. Obstet Gynecol Reprod Med; 20: 82-6.

18. Luyckx, M et al. (2014) First Series of 18 Pregnancies after Ulipristal Acetate Treatment for Uterine Fiborids. Fertil Steril; 1025: 1404-9.

19. Murad K. (2016) Spontaneous Pregnancy Following Ulipristal Acetate Treatment in Woman with a Symptomatic Uterine Fibroid. Obstet Gynaecol Can; 38 (1): 75-9.

20. Lo Monte $\mathrm{G}$ et al. (2016) Ulipristal Acetate Prior to in vitro Fertilization in a Female Patient Affected by Uterine Fibroids: a Case Report. Eur Rev Med Pharmacol Sci; 20(2): 202-7.

21. De la FuenteE et al. (2016) Ulipristal Acetate in Myomectomy Optimization in an Infertile Patient with Giant Myomas. Case Rep Med;Article ID 5135780.

22. De Gasperis-Brigante C et al. (2018) Pregnancy Outcomes Following Ulipristal Acetate for Uterine Fibroids: A Systematic Review. J Obstet Gynaecol Can; 40(8):1066-1076.e2 
(C) (P) This work is licensed under Creative Commons Attribution 4.0 License

To Submit Your Article Click Here: Submit Manuscript

DOI: 10.31579/jnmir.2021/004.
Ready to submit your research? Choose Auctores and benefit from:

* fast, convenient online submission

* rigorous peer review by experienced research in your field

* rapid publication on acceptance

* authors retain copyrights

* unique DOI for all articles

* immediate, unrestricted online access

At Auctores, research is always in progress.

Learn more www.auctoresonline.org/journals/new-medical-innovationsand-research 